\title{
Comparing Habitat Classification Schemes for Assessing Landscape Diversity
}

\author{
Athanasios S. KALLIMANIS ${ }^{1}$, Panayotis DIMOPOULOS ${ }^{1}$, Valeria TOMASELLI ${ }^{2}$, \\ Joao HONRADO ${ }^{3}$, Richard LUCAS ${ }^{4}$, Carmela MARANGI ${ }^{2}$ and Palma BLONDA ${ }^{2}$ \\ ${ }^{1}$ University of Ioannina, Agrinio/Greece \\ ${ }^{2}$ Consiglio Nazionale delle Ricerche (CNR), Bari/Italy \\ ${ }^{3}$ University of Porto/Portugal \\ ${ }^{4}$ Aberystwyth University/UK
}

This contribution was double-blind reviewed as extended abstract.

\begin{abstract}
One of the core European Union environmental policies is the creation and monitoring of the Natura 2000 network of protected areas. This network has been explicitly established for the preservation of conservation priority habitat types and species. Still the concept of habitat is a key concept for ecologists that remains ill defined and is notoriously hard to quantify and measure. Several classification schemes have been put forward, but their relative strengths and weaknesses remain less well examined. In this study we analyzed 8 different Natura 2000 sites (3 Greek, 2 Italian, 2 Portuguese, 1 British). Our study sites reflect a variety of ecosystems, most of them are Mediterranean ( 7 of the 8) and most of them are wetlands ( 6 of the 8 ). In each site, we classified habitats according to 4 different classification schemes (Annex I of the Habitats Directive, Corine Biotopes, EUNIS and General Habitat categories). Also, we used three other widely used land cover classification schemes (namely Corine Land Cover, FAO Land Cover Classification System and IGBP DIS scheme). We found that the different schemes produced considerably different values of landscape diversity leading even to different ranking of the sites according to their diversity. Furthermore, when comparing the landscape composition among sites according to the different schemes, they led to different inferences. Our results imply that the classification scheme used for estimating habitat composition plays an important role for the monitoring of protected areas, perhaps more important than previously assumed.
\end{abstract}

\section{Introduction}

The core European Union nature conservation policy is outlined in the Habitats Directive (92/43/EEC), which focuses on the conservation of biodiversity through preserving and restoring diversity and maintaining a favorable conservation status of the natural habitat types and species of community importance. To this end, EU Member States are obliged to report every six years the conservation status of the priority habitat types in their territory (as outlined in Article 17 of the Habitats Directive). This national assessment relies on many aspects of the habitat types with emphasis on changes in the area and range of these 
habitat types. The conservation of biodiversity at a European level should thus rely on a thorough investigation of the habitat type diversity patterns.

Despite this focus of EU policy on the preservation of 'natural habitat types', and although 'habitat' and 'habitat type' are terms essential for ecology and in use in the literature for decades, they are among the most confused in usage (Kallimanis et al. 2008). The confusion stems from the numerous definitions of habitat types, from the most common 'organismic-perspective' focusing on specific species or taxa, to the more rare cases where habitat types are considered as biodiversity surrogates or vegetation syntaxa. Most apllied conservation approaches follow the concept of the Habitats Directive (92/43/EEC) in which habitat types represent aspects of biodiversity to be monitored. This confusion is apparent not only in the ecological literature but also in the field of Geographic Information, where many alternative habitat classification schemes exist, potentially leading to significantly different habitat maps when applied in the same area. Since some of the major threats to biodiversity, such as fragmentation, habitat loss, rely on habitat mapping for their quantification, these differences in inference from the one habitat classification scheme to the other s become very important. In our study, we analyzed eight Natura 2000 protected areas in four European countries. For these sites we estimated their landscape composition and compared their landscape diversity according to four different habitat classification schemes and three alternative land cover classification schemes.

\section{Study Sites}

The overview of the characteristics of the eight areas analyzed in the present study shows that the array of selected sites reflect mainly the Mediteranean biogeographic region, but also include a site from the Atlantic biogeographic region. Most sites are wetlands but there are also mountainous sites (Tab. 1).

Table 1: Overview of the eight sites included in the analysis

\begin{tabular}{|l|l|l|c|c|r|}
\hline Site name & $\begin{array}{l}\text { Natura 2000 } \\
\text { site code }\end{array}$ & Type of site & $\begin{array}{c}\text { Number of } \\
\text { CLC classes }\end{array}$ & $\begin{array}{c}\text { Number of } \\
\text { habitat types }\end{array}$ & $\begin{array}{c}\text { Area } \\
\text { (ha) }\end{array}$ \\
\hline Kalamas Delta & GR2120001 & $\begin{array}{l}\text { River } \\
\text { estuaries }\end{array}$ & 18 & 6 & 8531 \\
\hline Kalodiki Fen & GR2120002 & Fen & 14 & 12 & 787 \\
\hline Kalamas Gorge & GR2120004 & River gorge & 13 & 14 & 1820 \\
\hline Murgia Alta & IT9120007 & Hill plateau & 10 & 6 & 125000 \\
\hline Le Cesine & IT9150032 & $\begin{array}{l}\text { Coastal } \\
\text { lagoons }\end{array}$ & 10 & 5 & 2148 \\
\hline $\begin{array}{l}\text { Rios Sabor e } \\
\text { Maçãs }\end{array}$ & $\begin{array}{l}\text { PTZPE0037 \& } \\
\text { PTCON0021 }\end{array}$ & $\begin{array}{l}\text { Montane } \\
\text { river site }\end{array}$ & 8 & 25 & 53009 \\
\hline Peneda-Gerês & $\begin{array}{l}\text { PTZPE0002 \& } \\
\text { PTCON0001 }\end{array}$ & $\begin{array}{l}\text { Mountainous } \\
\text { area }\end{array}$ & 10 & 22 & 94480 \\
\hline Cors Fochno & UK0014791 & Raised bog & 2 & 4 & 652 \\
\hline
\end{tabular}




\section{Habitat Classification Schemes}

Existing schemes for habitat mapping reflect the vagueness of the concept of 'habitat'. In the present study we analyzed four such schemes. The Corine Biotopes classification scheme is the oldest of these schemes. It is based on the phytosociological approach of vegetation classification. It is hierarchical with 3 or more levels. The Annex I of the Habitats Directive (92/43/EEC) defines a classification scheme for the natural habitat types of EU to be preserved in the Natura 2000 network of protected areas. This system is of a conservation focus, with a subset of the classes representing priority habitat types (i.e. habitat types in danger of disappearance and whose range mainly falls within EU) that are explicitly protected by European and National law. The system is specialized only for natural and seminatural habitat types (often representing phytosociological descriptions of vegetation coverage) and does not offer complete coverage of the landscapes. The EUNIS (European Nature Information System) Habitat Types classification is a comprehensive pan-European system for habitat identification. It covers all types of habitats from natural to artificial, from terrestrial to freshwater and marine. The General Habitat Categories (GHCs) classification system has been recently developed by BUNCE et al. (2008), for consistent in-field habitat surveillance and monitoring and appears highly suitable also for habitat change mapping from remote sensing. The GHCs are based on Life Forms. The system includes both natural and artificial habitats.

Also for the same sites we used three widely used landcover classification schemes (namely Corine Land Cover, FAO Land Cover Classification System and IGBP DIS scheme). The Corine Land Cover Landscape thematic content and resolution was defined by the European Environment Agency. It is a closed, hierarchical system with 44 classes in its finest resolution, which places equal emphasis to human dominated land uses and natural vegetation classes. The International Geosphere-Biosphere Programme (IGBP) DISCover classification scheme is a relatively coarse classification with 17 classes. This scheme places more emphasis on natural vegetation (13 classes) and less on human land uses (3 classes) and has 1 class for unidentified land cover. It does not cover marine habitats at all and it has been applied at a global scale. The Food and Agriculture Organization of the United Nations (FAO) developed a Land Cover Classification System (LCCS) (DI GREGORIO \& JANSEN 2005), based on the use of a set of diagnostic criteria for a parametric classification approach. The system can be distinguished in two stages: the dichotomous phase (where a dichotomous key identifies 8 major land cover categories) and the modularhierarchical phase (which is open ended and where a set of environmental classifiers allows the definition of more detailed land cover classes).

For each scheme we estimated the landscape composition of each of the 8 sites, and quantified landscape diversity as the number of different classes recorded in each site. To compare the ranking of the sites according to the different schemes we used Spearman rank correlation. Also we performed pair-wise comparisons of the landscape composition of these sites using Jaccard similarity index, which is the number of landscape classes common to both sites divided by the total number of classes observed in the pair of sites. To compare the similarity matrix we used Mantel test. 


\section{$4 \quad$ Results and Discussion}

We found that the landscape diversity estimates based on the different classification schemes were non-congruent. Especially the Annex 1 classification scheme led to considerable differences in the ranking of sites according to landscape diversity in comparison to the other schemes (it was not correlated to the diversity of Corine land cover classes $\mathrm{p}=0.82$; neither to Corine biotope classes $\mathrm{p}=0.07$; nor to General habitat categories $\mathrm{p}=0.06$; nor to FAO LCCS classes p=0.46). The habitat diversity sensu Annex 1 scheme is the legal basis for the protected areas designation. Especially sites with large proportion of human land uses displayed the greatest changes in their ranking mainly due to the fact that while most schemes explicitly account for them, Annex 1 ignores them altogether. Similarly, noncongruent was the estimates of the similarity among sites according to the different classification schemes. Sites that appear most similar according to one scheme (e.g. Annex 1) may appear least similar according to other schemes (e.g. Corine Land Cover), and this was supported by the results of the Mantel tests (e.g. for the comparison between Annex 1 habitats and Corine land cover classes $\mathrm{p}=0.108$ ).

Habitat diversity is often cited as a driver of biodiversity (TRIANTIS et al. 2003). However, there is a lack of empirical studies examining this relationship. A major reason is the difficulty of quantifying habitat diversity of an area. Our results highlight that the choice of habitat classification scheme directly affects these quantification attempts, and thus it affects the outcome of any ecological analysis of the effects of habitat diversity. Another implication of our results is that it is anything but straightforward to use one classification scheme as a surrogate for another, and especially for the Annex 1 classification scheme. This is especially important since Annex 1 classification relies heavily on field data that cannot be retrieved from remote sensing data. And thus makes habitat mapping for the purpose of Article 17 reporting a difficult task.

\section{References}

Bunce, R. G. H., Metzger, M. J., Jongman, R. H. G., Brandt, J., De Blust, G., ElenaRossello, R., Groom, G. B., Halada, L., Hofer, G., Howard, D. C., Kovář, P., Mücher, C. A., PadoA-Schioppa, E., PaelinX, D., Palo, A., Perez-Soba, M., Ramos, I. L., ROCHE, P., SKÅNES, H. \& WRBKA, T. (2008), A standardized procedure for surveillance and monitoring European habitats and provision of spatial data. Landscape Ecology, 23, 11-25.

Di Gregorio, A. \& JAnsen, L. J. M. (2005), Land Cover Classification System (LCCS): classification concepts and user manual. Food and Agriculture Organization of the United Nations, Rome.

Kallimanis, A. S., Mazaris, A. D., Tzanopoulos, J., Halley, J. M., Pantis, J. D. \& SGARDELIS S. P. (2008), How does habitat diversity affect the species - area relationship? Global Ecology Biogeography, 17, 532-538.

Triantis, K. A., Mylonas, M., LiKA, K. \& Vardinoyannis, K. (2003), A model for the species-area-habitat relationship. Journal of Biogeography, 30, 19-27. 